\title{
Pesquisa em contextos de ensino e aprendizagem por meio do uso da internet: uma ecologia de saberes ${ }^{1}$
}

\author{
Petrilson A. Pinheiro²
}

\section{Resumo}

Tendo em vista o interesse crescente de pesquisas nas humanidades e ciências sociais que lidam especificamente com contextos empíricos de ensino e aprendizagem e uso de tecnologias digitais da informação e da comunicação em entender práticas, condições e impactos do uso da internet em instituições de educação básica, o objetivo deste artigo é promover uma discussão sobre o processo de produção acadêmica, em particular o que se relaciona a práticas de letramentos que envolvem contextos empíricos escolares por meio do uso da internet. Para tanto, busca-se como recurso teórico-metodológico desenvolver uma discussão epistemológica, de caráter qualitativo, sobre a noção de conhecimento(s), organizando-a com base nos conceitos foucaultianos de savoir e connaissance, na concepção plural de epistemologia e na noção de letramento crítico, a fim de (re)pensar o processo de construção de conhecimentos no próprio ato de fazer pesquisa em contextos de ensino e aprendizagem a partir da perspectiva de uma ecologia de saberes. Considerase, ao final, que tal perspectiva nos possibilita repensar a pesquisa sob dois pontos fundantes: o primeiro é o seu caráter qualitativo, visto que as pesquisas qualitativas buscam descrever e compreender o mundo das práticas dos participantes envolvidos na investigação; o segundo, o seu caráter sociopolitico, posto que a realização de pesquisas empíricas em contextos de ensino e aprendizagem por meio da internet pode contribuir para o desenvolvimento tanto da educação básica quanto a educação superior.

\section{Palavras-chave}

Ecologia de saberes - Epistemologias - Pesquisa empírica - Internet - Escola.

1- Agradeço à Fundação de Amparo à Pesquisa do Estado de São Paulo (Fapesp) pela concessão da bolsa de pesquisa no exterior que possibilitou a elaboração do presente artigo (número do processo: 2016/19123-3).

2- Universidade Estadual de Campinas (Unicamp), Campinas, São Paulo, Brasil. Contato: petrilson@iel.unicamp.br; ORCID ID: https://orcid. org/0000-0002-4066-9636

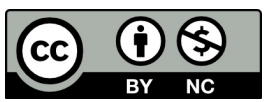




\section{Research in Internet-based teaching and learning contexts: an ecology of knowledge skills}

\section{Abstract}

In view of the growing interest of researches in humanities and social science dealing specifically with teaching and learning empirical contexts and the use of digital information and communication technologies, to understand practices, conditions and impacts of Internet use in education, this article aims to discuss the academic production, especially those related to literacy practices involving empirical contexts in schools through the use of Internet. To do so, a theoretical-methodological framework is utilized to develop a qualitative epistemological discussion about knowledge based on the Foucauldian concepts of savoir and connaissance, on the plural conception of epistemology, and on the notion of critical literacy, so as to (re)think the very knowledge construction in the perspective of an ecology of knowledge skills. One considers that this perspective allows us to rethink research based on two founding points: the first one is its qualitative nature, since qualitative studies seek to describe and understand the practices of the participants involved in any investigation; and second, its socio-political dimension, since empirical studies in online teaching and learning contexts can contribute to the development of both basic and higher education.

\section{Keywords}

Ecology of knowledge skills - Epistemologies - Empirical research - Internet - School.

\section{Introdução}

Tem havido um interesse crescente de pesquisas nas humanidades, quantitativas e qualitativas, que lidam especificamente com contextos empíricos de ensino e aprendizagem e uso de tecnologias digitais da informação e da comunicação (TDIC), em entender, de alguma forma, práticas e condições de uso de TDIC nas instituições de educação básica. Seja para observar e analisar dificuldades de implantação e desenvolvimento de projetos de letramentos digitais, propondo também alternativas para solucionar essas dificuldades, seja para mostrar práticas que, de alguma forma, já têm sido bem-sucedidas, com ou sem intervenção acadêmica, as pesquisas empíricas realizadas por universidades e centros de pesquisa têm tido um impacto relativamente importante para educação básica ${ }^{3}$.

\footnotetext{
3- Não incluo aqui diversas pesquisas de caráter documental (análise de documentos oficiais e materiais didáticos, por exemplo), que, assim como muitas de natureza empírica, muito têm contribuído também para repensar práticas e currículos da educação básica.
} 
Contudo, devo destacar também que se, por um lado, a academia tem se empenhado para conhecer e buscar propostas para aprimorar práticas e condições de ensino e aprendizagem em diferentes contextos da educação básica, por meio da produção de um certo tipo de conhecimento científico, por outro, é preciso saber o quanto desse conhecimento produzido pela academia, de fato, dialoga com os atores sociais que deveriam ser diretamente envolvidos e afetados, isto é, gestores e, sobretudo, professores e alunos da educação básica. Nesse sentido, levanto a seguinte pergunta: dos trabalhos produzidos na academia (artigos, monografias, dissertações e teses), quantos são, de fato, compartilhados com os sujeitos participantes das pesquisas que os geraram, não se limitando a serem usados para engordar o Currículo Lattes em apresentações de congressos e em publicações de revistas acadêmicas nacionais e internacionais?

Uma possível resposta a essa pergunta será dada ao longo deste artigo, em que discuto o processo de produção acadêmica, em particular o que se relaciona a pesquisas sobre práticas de letramentos escolares e uso da internet. Para tanto, busco como recurso teórico-metodológico desenvolver uma discussão epistemológica, de caráter qualitativo, sobre a noção de conhecimento(s), organizando-a, primeiramente, com base nos conceitos foucaultianos de savoir e connaissance; em seguida, relaciono esses conceitos a uma noção plural de epistemologia e de letramento crítico, para, então, (re)pensar, tomando como exemplo concreto de como lidar com a informação que circula na internet (a enciclopédia on-line Wikipédia), o processo de construção de conhecimentos no próprio ato de fazer pesquisa em contextos de ensino e aprendizagem a partir da perspectiva de uma ecologia de saberes. Por fim, concluo o artigo, buscando mostrar que tal perspectiva nos possibilita repensar a pesquisa empírica sob dois pontos fundantes: o primeiro é o seu caráter qualitativo, visto que as pesquisas qualitativas buscam descrever e compreender o mundo das práticas dos participantes envolvidos na investigação; o segundo, o seu caráter sociopolítico, posto que a realização de pesquisas empíricas em contextos de ensino e aprendizagem por meio da internet pode contribuir para o desenvolvimento tanto da educação básica quanto a educação superior.

\section{Epistemologias: teorizando conhecimentos para uma ecologia dos saberes}

A concepção de epistemologia (no singular), como estudo ou teoria do conhecimento, ocupa-se basicamente em entender o que a noção de conhecimento abarca. Nessa perspectiva, a primeira questão que se antepõe é o reconhecimento de que o verbo conhecer apresenta tanto um sentido proposicional - de descobrir algo com base em proposições (premissas e juízos que se formam por meio de valores de verdade, isto é, verdadeiro ou falso -, quanto processual - questão de ordem prática e performativa de saber como realizar alguma ação para perceber e alcançar algum fim.

Muito embora ambos os sentidos sejam relevantes para a compreensão do conhecimento de forma mais ampla, apenas o primeiro (o proposicional) é privilegiado na epistemologia filosófica tradicional. Contudo, é preciso problematizar essa concepção de epistemologia para que se possa dar conta da multiplicidade e da inter-relação no 
fazer pesquisa, em particular, e na vida social, em geral. Um modo possível de iniciar essa problematização é tomar como base a diferença entre os conceitos foucaultianos de saber (savoir) e conhecimento (connaissance) ${ }^{4}$. Para Foucault (2008 [1966], p. 204-205), um saber

\begin{abstract}
É aquilo de que podemos falar em uma prática discursiva que se encontra assim especificada: o domínio constituído pelos diferentes objetos que irão adquirir ou não um status científico; [...] um saber é, também, o espaço em que o sujeito pode tomar posição para falar dos objetos de que se ocupa em seu discurso; [...] um saber é também o campo de coordenação e de subordinação dos enunciados em que os conceitos aparecem, se definem, se aplicam e se transformam; [...] Há saberes que são independentes das ciências (que não são nem seu esboço histórico, nem o avesso vivido); mas não há saber sem uma prática discursiva definida, e toda prática discursiva pode definir-se pelo saber que ela forma.
\end{abstract}

Para Foucault, o saber, então, estaria relacionado aos processos de conhecimento do sujeito, que se constituem em práticas discursivas que nunca são fixas, porquanto estão sempre em constante mudança devido a modificações que sofrem durante esses próprios processos de conhecimento. 0 conhecimento, por outro lado, corresponderia à constituição de discursos responsáveis pela construção de um processo complexo de racionalização, de identificação e de classificação dos objetos. Nesse sentido, o conhecimento é entendido como relativamente rígido e estagnado.

Dentro dessa visão, diferentemente do conhecimento, o saber não se funda em um princípio (não, pelo menos, em um princípio científico), uma vez que não precisa ser resultado ou produto de um método de pesquisa confiável. Por isso, um saber não é avaliado como genuíno ou não com base em procedimentos científicos - modos de conhecimento relacionados a aparatos altamente desenvolvidos para justificar ou provar algo (por exemplo, sua validação como verdadeiro ou falso) -, mas sim por meio de múltiplas experiências constitutivas das práticas sociais dos sujeitos, das quais a ciência é apenas uma parte (em muitos contextos, uma parte mínima e até inexistente).

Ao propor uma arqueologia do saber, Foucault justamente procura se debruçar sobre o conceito de saber, que

[...] ao invés de percorrer o eixo consciência-conhecimento-ciência (que não pode ser liberado do index da subjetividade), a arqueologia percorre o eixo prática discursiva-saber-ciência. Enquanto a história das ideias encontra o ponto de equilíbrio de sua análise no elemento do conhecimento (encontrando-se, assim, coagida a reencontrar a interrogação transcendental), a arqueologia encontra o ponto de equilíbrio de sua análise no saber - isto é, um domínio em que o sujeito é necessariamente situado e dependente, sem que jamais possa ser considerado titular. (FOUCAULT, 2008 [1966], p. 205).

4- Embora os conceitos de savoir e connaissance apresentem uma certa inconsistência ao longo da obra de Foucault, sobretudo em seu livro Arqueologia do Saber, considero que a diferenciação conceitual proposta pelo autor é bastante pertinente para a discussão epistemológica que proponho fazer neste texto. Para uma discussão mais aprofundada sobre essa questão, ver FABION, James D. Essential works of Foucault: aesthetics, method, and epistemology. v. II. New York: New York Press, 1998. 
Pode-se, desse modo, inferir que, para Foucault, a arqueologia não se constitui como um domínio de coisas conhecidas, mas de coisas a serem conhecidas, de uma maneira ou de outra, cujo rigor varia de acordo com os contextos em que são forjadas. Nesse sentido, o saber, elemento prototípico da arqueologia, não se forma com base em "sistemas de postulados que governam todos os ramos de conhecimento.” (FOUCAULT, 2008 [1966], p. 195); produz-se a partir de muitas divisões e subdivisões, uma constelação de outros saberes constitutivos de territórios arqueológicos, que contêm não apenas demonstrações, mas podem apresentar um feixe de relações que envolvem "ficções, reflexões, narrativas, regulamentos institucionais, decisões políticas.” (FOUCAULT, 2008 [1966], p. 205).

Essa noção de arqueologia é aqui particularmente relevante para entender e repensar o próprio conceito de episteme, que, Para Foucault (2008 [1966], p. 214-215), não se constitui como um sistema de postulados, mas sim como um "campo indefinido de relações; um conjunto indefinidamente móvel de escansões, defasagens, coincidências, que se estabelecem e se desfazem". Esse conjunto, que se forma nas conexões entre práticas discursivas e ciências, sempre permeadas por relações de poder, é o que, segundo o autor, torna, então, possível a existência de figuras epistemológicas.

Essa tentativa de expansão conceitual de episteme, que resulta no que Foucault chama de figuras epistemológicas, parece dialogar com a ideia de conhecimento proposta por Sousa Santos (2006), como corolário da experiência social; portanto, conhecimento não como connaissance, mas como savoir. Para o autor,

Toda a experiência social produz e reproduz conhecimento e, ao fazê-lo, pressupõe uma ou várias epistemologias. Epistemologia é toda a noção ou ideia, reflectida ou não, sobre as condições do que conta como conhecimento válido. É por via do conhecimento válido que uma dada experiência social se torna intencional e inteligível. Não há, pois, conhecimento sem práticas e actores sociais. E como umas e outros não existem senão no interior de relações sociais, diferentes tipos de relações sociais podem dar origem a diferentes epistemologias. (SOUSA SANTOS, 2006, p. 9).

Nessa concepção de epistemologia - ou melhor, de (diferentes) epistemologias - não se pode, segundo Sousa Santos e Meneses (2009, p. 7), defender a ideia de que haveria epistemologias neutras, pois aquelas que reclamam sê-lo seriam as menos neutras. Para os autores, "a reflexão epistemológica deve incidir não nos conhecimentos em abstracto, mas nas práticas de conhecimento e nos seus impactos noutras práticas sociais”.

No entanto, para que a reflexão epistemológica incida, de fato, nas práticas de conhecimento, ou no savoir, para Foucault, permitindo-se, assim, promover uma arqueologia do saber, é preciso problematizar a própria relação teoria-prática. Isso se coaduna com a visão de Deleuze, que, em uma conversa com Michel Foucault, aponta que

As relações teoria-prática são muito mais parciais e fragmentárias. Por um lado, uma teoria é sempre local, relativa a um pequeno domínio e pode se aplicar a um outro domínio, mais ou menos afastado. A relação de aplicação nunca é de semelhança. Por outro lado, desde que uma teoria penetre em seu próprio domínio encontra obstáculos que tornam necessário que seja revezada por outro tipo de discurso (é este outro tipo que permite eventualmente passar a um domínio diferente). 
A prática é um conjunto de revezamentos de uma teoria a outra e a teoria um revezamento de uma prática a outra. Nenhuma teoria pode se desenvolver sem encontrar uma espécie de muro e é preciso a prática para atravessar o muro. (DELEUZE, in FOUCAULT, 1982, p. 69).

A possibilidade de a teoria atravessar o muro está, a meu ver, intrinsicamente relacionada à sua vontade e humildade de enxergar e, de fato, lidar com as práticas da vida social, o que poderia tornar a prática o "próprio palco de criação de reflexões teóricas, ou seja, neste âmbito, teoria e prática não são coisas diferentes. A teoria é relevante para a prática porque é concebida dentro da prática." (RAJAGOPALAN, in SILVA et al., 2011, s/n).

Nessa perspectiva, entender as relações teoria-prática como constitutivas de um processo de investigação, e não como categorias estanques, traz mais do que um novo olhar sobre um determinado objeto de pesquisa; isso constrói um novo objeto de pesquisa, uma vez que, inevitavelmente, nos leva a (re)formular novas perguntas de pesquisa e novos objetivos, o que, por sua vez, nos leva a rever e até inovar percursos teóricos e métodos de geração e de análise de dados.

Contudo, tais inovações na construção do objeto de pesquisa não são tributárias apenas de escolhas metodológicas ou teóricas, como se as opções do fazer pesquisa devessem ser teleologicamente orientadas por/para um determinado método ou teoria. Trata-se, pois, de discutir a própria noção de epistemologia; não aquela que historicamente escamoteou de sua constituição e reflexão os contextos social, cultural e político da (re) produção do conhecimento, mas aquela (noção) que procura repensá-los com base em diferentes relações e práticas sociais.

Para entender de maneira mais ampla e complexa a construção de conhecimentos, sobretudo no próprio ato de fazer pesquisa, é preciso, pois, buscar promover diálogos entre saberes, valorizando inclusive aqueles que historicamente foram negligenciados e vilipendiados do processo de formação do conhecimento científico moderno. Esses diálogos heterárquicos seriam, segundo Sousa Santos (2006) e Sousa Santos e Meneses (2009), a base de uma ecologia de saberes. Para os autores, a ideia de uma ecologia dos saberes se baseia no

[...] reconhecimento da pluralidade de conhecimentos heterogêneos (sendo um deles a ciência moderna) e em interações sustentáveis e dinâmicas entre eles sem comprometer a sua autonomia. A ecologia de saberes baseia-se na ideia de que o conhecimento é interconhecimento. (SOUSA SANTOS; MENEZES, 2009, p. 44-45).

É justamente por buscar (re)conhecer a diversidade epistemológica que existe mundo, muito além do conhecimento científico, que procurar uma epistemologia geral seria não apenas algo contraproducente, mas, sobretudo, incompleto e insuficiente para lidar com a formação (inter-relação) e validação de conhecimentos. Todavia, mesmo sendo relacional e plural, a ecologia dos saberes não pressupõe que os diálogos entre os diferentes saberes sejam sempre heterárquicos; há, de fato, hierarquia entre saberes, mas esta se relaciona à produção de conhecimentos concretos e se situa em contextos específicos. A esse respeito, Sousa Santos e Meneses (2009, p. 50) aponta que: 
A ecologia de saberes não concebe os conhecimentos em abstracto, mas antes como práticas de conhecimento que possibilitam ou impedem certas intervenções no mundo real. Contudo, em lugar de subscrever uma hierarquia única, universal e abstracta entre os saberes, a ecologia de saberes favorece hierarquias dependentes do contexto, à luz dos resultados concretos pretendidos ou atingidos pelas diferentes formas de saber. Hierarquias concretas emergem do valor relativo de intervenções alternativas no mundo real. Entre os diferentes tipos de intervenção pode existir complementaridade ou contradição.

Por se dar em práticas reais e concretas de produção de conhecimentos, onde sempre pode haver complementariedade e embates entre diferentes saberes, torna-se, portanto, evidente a necessidade de pluralizar a palavra epistemologia, conforme o faz Signorini (2015, p. v), ao questionar o porquê de se falar em epistemologias e não em métodos ou modelos. A autora assevera que tal questão "é de interesse para a pesquisa no campo aplicado porque está relacionada à metareflexividade, cada vez mais necessária e urgente: que tipo de conhecimento se está produzindo com e sobre a lingua(gem)? Como? Com base em quê? Em benefício (ou prejuízo) de quem?"

Essas perguntas suscitadas por Signorini me levam a questionar a própria natureza da (re)produção de conhecimento. Isso porque, não há, de fato, "conhecimento que não seja conhecido por alguém para alguns objectivos. Todos os conhecimentos sustentam práticas e constituem sujeitos" (SOUSA SANTOS; MENESES, 2009, p. 49). Com efeito, tais questões permitem vislumbrar a possibilidade de situar e historicizar um objeto de investigação, mas também de lançar sobre ele um olhar crítico que, em última análise, possibilita uma transformação desse próprio objeto.

Um modo, a meu ver, profícuo de buscar promover tal transformação é trazer para a pesquisa de caráter empírico uma noção plural relacional de conhecimento (epistemologias) em contextos de ensino e aprendizagem por meio do uso de TDIC. Isso possibilita não apenas produzir uma mudança tecnológica ou metodológica nas práticas de letramentos escolares, mas, de fato, produzir uma ecologia de saberes.

\section{Ecologia de saberes e TDIC: repensando pesquisa na/para a escola}

Buscando, então, estabelecer uma relação entre a discussão aqui feita e a pesquisa e o ensino, levanto a seguinte questão: como a pesquisa empírica, de caráter práticoteórico, poderia contribuir para explorar e promover o uso de TDIC, em um ambiente da Web 2.0, em que alunos e professores podem ser, ao mesmo tempo, produtores, difusores e consumidores de textos, no contexto escolar?

Com efeito, as TDIC têm fortemente impactado a vida social e cultural de nossas sociedades, sobretudo após o advento e consolidação da Web 2.0 (O'REILLY, 2005), em que novos mecanismos vêm sendo criados, possibilitando, assim, uma nova era de transinformação $0^{5}$. Isso permite novas condições técnicas e socioculturais para a ampliação

5- Estou chamando de era da transinformação o momento sócio-histórico atual, em que a informação não apenas circula em uma rede global (rede mundial de computadores), mas também sofre metamorfoses por parte de qualquer usuário, tornando-se cada vez mais fluida e multifacetada, num processo de retroalimentação contínuo que transforma a si mesma. 
de práticas comunicativas no mundo digital, nas quais as pessoas não apenas recebem, mas também publicam informações no sistema, desconstruindo-se, assim, as próprias categorias tradicionais de autor e de leitor.

Contudo, mesmo diante dessas mudanças nas práticas de letramento impulsionadas por transformações sociais, culturais e tecnológicas, a escola, por outro lado, parece ser uma das poucas instituições que ainda resistem a essas transformações, pois opera com práticas grafocêntricas que, em geral, não refletem essas mudanças. Por isso, a instituição escolar se encontra diante da necessidade de repensar sua funcionalidade, reavaliar suas estratégias e (re)inventar suas práticas, com o fito de tentar responder às exigências multifacetadas dessa nova era digital, que se reorganiza de forma cada vez mais dinâmica e redefine novos papéis institucionais cada vez mais inter-relacionados com os usos das TDIC que emergem no cenário atual do mundo globalizado.

Nas pesquisas empíricas que venho realizando nos últimos anos, junto a alunos de pós-graduação no contexto da educação básica pública (PINHEIRO; FELICIO, 2016; PINHEIRO, 2015; PINHEIRO; GOMES, 2015; PINHEIRO; RICARTE, 2014; PINHEIRO, 2013, apenas para citar algumas), temos percebido que a questão do uso de TDIC na escola vai muito além do acesso à tecnologia. Nesse sentido, por exemplo, a instalação de laboratórios de informática equipados com internet e programas sofisticados em escolas públicas não basta para tornar os alunos letrados na sociedade atual cada vez mais hiperssemiotizada, pois, além de investimento material, é preciso haver, sobretudo, investimento humano. Isso quer dizer que, se por um lado tem havido um certo empenho institucional para levar tecnologia às escolas públicas brasileiras, por outro, parece haver uma certa negligência em relação a uma outra questão de suma importância: a falta de um melhor preparo dos próprios profissionais da educação, mormente dos professores, que, em geral, ainda não sabem como fazer com que essa tecnologia que chega às escolas possa se tornar, de fato, produtiva para o processo de ensino-aprendizagem.

Nesse sentido, apesar de os professores estarem realmente envolvidos em um trabalho rigoroso e complexo, muito mais do que em qualquer época anterior, é muito comum os educadores não serem devidamente reconhecidos. Em geral, eles não são apoiados, compensados ou promovidos com base nos trabalhos realizados nas suas próprias escolas. Além disso, não raro, os professores trabalham com materiais didáticos de forma inflexível, o que desencoraja qualquer tipo de inovação e restringe oportunidades de consultar outros colegas e de realizar um trabalho colaborativo interdisciplinarmente.

Destarte, nesse cenário, deve-se considerar que a simples inserção de novas tecnologias na escola, por si só, não é capaz de garantir um trabalho bem-sucedido na escola. Em outras palavras, as novas tecnologias não irão, por si só, criar "inovação e novos espaços para a aprendizagem. 0 potencial da mídia digital só pode ser percebido se estiver ancorado em um contexto pedagógico, social e organizacional apoiado por um compromisso político" (SØBY, 2008, p. 129).

Esse compromisso politico a que o autor se refere está, por um lado, relacionado à compreensão de que as transformações de ordem social, política e cultural são também o corolário de processos de globalização, incluindo a ubiquidade das TDIC. Todavia, se essa relação for feita de forma muito direta, sem que se considerem os matizes que compõem 
tais processos, corremos risco de sermos guiados por uma perspectiva que se enquadra exclusivamente na dinâmica de reestruturação do capitalismo, que se consolida no modelo vigente neoliberal. A esse respeito, Sousa Santos e Meneses (2009, p. 11) assevera que:

[...] o capitalismo global, mais que um modo de produção, é hoje um regime cultural e civilizacional, portanto, estende cada vez mais os seus tentáculos a domínios que dificilmente se concebem como capitalistas, da família à religião, da gestão do tempo à capacidade de concentração, da concepção de tempo livre às relações com os que nos estão mais próximos, da avaliação do mérito científico à avaliação moral dos comportamentos que nos afectam.

Por ter se tornado cultural e civilizacional, o capitalismo global pode justamente nos conduzir à criação de modelos de educação que se incorporam a lógicas mercadológicas, sugeridas e, em alguns casos, até impostas, por grandes conglomerados e corporações internacionais. Nessas lógicas mercadológicas, práticas de competitividade, produtividade e utilitarismo, que estão na base do discurso neoliberal, podem, em última instância, transformar a educação em commodities do mundo globalizado, cujo papel seria mais direcionado e dimensionado de acordo com sua utilidade e função que desempenharia no/ para o mercado.

Uma possibilidade de pensar o uso de TDIC na escola, que busque retirar a "aura" mercadológica da educação, seria entender os letramentos escolares na perspectiva ideológica proposta por Street (1984), cujas práticas socioculturais são tomadas como diversas e múltiplas, não só as legitimadas pela escola, e entendidas por meio da reconstrução de suas histórias, culturas locais e dos significados que são atribuídos pelos sujeitos nessas práticas. A esse respeito, o autor aponta que é preciso reconhecer que os múltiplos letramentos

[...] variam no tempo e no espaço, mas são também constatados nas relações de poder. Assim, os Novos Letramentos não pressupõem coisa alguma como garantia em relação aos letramentos e às práticas sociais com que se associam, problematizando aquilo que conta como letramento em qualquer tempo-espaço e interrogando-se sobre quais letramentos são dominantes e quais são marginalizados ou de resistência. (STREET, 2003, p. 77).

Ao reconhecer a multiplicidade de letramentos, tanto os valorizados como os não valorizados na/pela instituição escolar, essa perspectiva de letramento se constitui como uma ecologia de saberes, isto é, como espaços de utopias de interconhecimento, nos quais se aprendem outros "conhecimentos sem esquecer os próprios. Ela convida a uma reflexão mais profunda sobre a diferença entre a ciência como conhecimento monopolista e a ciência como parte de uma ecologia de saberes." (SOUSA SANTOS; MENESES, 2009, p. 47).

Entender a ciência na perspectiva da ecologia dos saberes é, portanto, um desafio de autorreflexão para todos os pesquisadores que investigam contextos de ensino e aprendizagem, pois, como propor investigações, métodos e alternativas de ensino inovadoras, que buscam, de alguma forma, questionar a reprodução do conhecimento escolar, se, na academia, muitas vezes se lida com um conhecimento monopolista, que 
não possibilita inter-relação com outros saberes e, menos ainda, se comunica para além dos muros universitários?

Ao propor, neste artigo, lidar com ecologia de saberes por meio da internet, busco dar uma resposta promissora a tal pergunta, na medida em que algumas das questões que dizem respeito, por exemplo, à produção, difusão e consumo de informação na atualidade me obriga a repensar a minha própria condição de (re)produtor de conhecimento, em especial quando estou exercendo o papel de professor.

Refletir sobre essas questões me impulsiona, por sua vez, a fazer outra pergunta: o que é ser letrado hoje? Com efeito, é preciso entender que as pessoas estão cada vez mais em simbiose com as TDIC, sobretudo os mais jovens, que, por serem nativos digitais (PRENSKY, 2001), têm, em geral, muito mais facilidade para lidar com questões técnicas relacionadas ao uso da internet do que um adulto. Contudo, em geral, falta a esse aluno desenvolver olhar crítico sobre o uso que faz do que circula no ciberespaço. 0 que quero dizer é que, muito mais do que buscar informação na rede - o que muitos jovens de hoje parecem fazer muito bem - é necessário educá-los para uma análise crítica das informações com as quais eles lidam ou podem vir a lidar. A esse respeito, Pinheiro (2015, p. 212) assevera que:

[...] o "ser letrado crítico" está, mais do nunca, relacionado ao fato de que o ciberespaço pode ser útil tanto para divulgar informações relevantes, quanto informações de caráter duvidoso (do ponto de vista conceitual, quanto ideológico). Nesse sentido, o que difere um simples usuário de um letrado crítico é o fato de o primeiro estar apenas interessado em buscar informações na rede, enquanto o segundo, por outro lado, se mostra também preocupado com a análise e avaliação das fontes de informações disponibilizadas no mundo digital. "Ser letrado crítico" se torna, por conseguinte, um sujeito que não apenas reconhece e transita por diferentes espaços hipertextuais, mas busca compreender os diferentes mecanismos que regem a produção, reprodução e difusão do que circula na rede.

Um exemplo interessante é o da Wikipédia. 0 fato de se constituir de maneira tão efêmera e multifacetada torna a enciclopédia on-line mais acessada do mundo um ambiente, em princípio, não apenas de consumo, mas de desconfiança. Comparo aqui a Wikipédia com a (não atualmente) tão conhecida Enciclopédia Barsa, cujo conteúdo é (e sempre foi) associado a uma espécie de verdade inquestionável. Com efeito, devo lembrar que, quando se usava (ou ainda se usa) a enciclopédia para realizar alguma tarefa de pesquisa escolar, não se costuma(va) questionar se as informações trazidas em seus verbetes estão(vam) corretas ou não.

Com a popularização da internet nos últimos anos e o avanço da Web 2.0, passou a haver não apenas uma facilidade para manusear grande variedade de conteúdos on-line, mas, sobretudo, a possibilidade de produção, publicação e republicação de informações por qualquer usuário. A Wikipédia é um dos exemplos emblemáticos da fase da web, cujo processo de produção dos verbetes, diferentemente da Enciclopédia Barsa, é controlado pelos próprios usuários da internet, o que, portanto, poderia levar muitas pessoas, em particular, professores, a desconfiarem do conteúdo produzido apresentado pela plataforma. 
No entanto, essa disposição de espírito (falta de confiança) em relação à Wikipédia apenas poderia fazer sentido na lógica de reprodução e aquisição do conhecimento monopolista a que me referi acima. Na perspectiva da ecologia de saberes, porém, isso estaria fora de questão, pois o caráter efêmero e multifacetado da inteligência coletiva, na qual se inscreve o processo de produção colaborativa de escrita da enciclopédia on-line, está subjacente a tal perspectiva.

Assim, ao invés de simplesmente desconfiar e descartar a Wikipédia, seria possível, nesse caso, explorar questões bastante relevantes, como as interfaces entre letramentos escolares grafocêntricos e letramentos hipermidiáticos, discutindo, por exemplo, os processos de busca e circulação de informação na internet, que envolvem desde a escolha e filtragem de conteúdo on-line, passando pela compreensão dos resultados de busca, até a avaliação crítica das fontes encontradas, em que poderiam ser problematizadas a questão do plágio e a própria questão ética em meio ao fluxo de informação no mundo digital.

Nesse sentido, a ideia da ecologia de saberes me parece bastante adequada para entender a natureza e o modus operandi da Wikipédia, pois nos impulsiona a ir além do consumo irrefletido ou da rejeição (por desconfiança); possibilita-nos discutir e analisar seu conteúdo de forma crítica - o que pouco se fazia com os textos impressos. Em outras palavras, estamos vivenciando uma (nova) era em que, para ser letrado (digital), não basta apenas reconhecer e consumir conteúdos que circulam na internet, mas também buscar compreender e avaliar os diferentes mecanismos que regem a produção, reprodução e difusão desses conteúdos.

Um olhar interessante e promissor para lidar com a questão dos letramentos digitais dentro dessa concepção parece ser o do letramento crítico, um conceito que desempenha um papel fundamental no processo de emancipação e formação de professores e estudantes críticos. Alguns autores (GEE, 1996; CERVETTI; PARDALES; DAMICO, 2001; LUKE, 2004) propõem uma visão de letramento crítico fortemente influenciada pela teoria crítica social de Paulo Freire (1982), cujo objetivo é considerar os letramentos como práticas sociodiscursivas que permitem uma compreensão crítica e um questionamento de forças e construtos ideológicos, de modo a empoderar e transformar indivíduos.

Dentro dessa visão, o conceito de letramento crítico é baseado na ideia de que as representações são sempre ideológicas, que influenciam e constituem as práticas sociais, e que os sujeitos nelas envolvidos devem estar conscientes de tais representações, de modo a aprender a se posicionarem criticamente sobre elas (CERVETTI; PARDALES; DAMICO, 2001). Nesse sentido, ser letrado significa ser crítico. Isso abre a possibilidade de "estar não apenas no mundo, mas com o mundo", em que "o indivíduo não é um espectador”, mas um "recriador" (FREIRE, 1982, p. 53).

Essa perspectiva de letramento crítico, a meu ver, se coaduna com a ideia de uma ecologia de saberes, constituinte e condizente com um mundo epistemologicamente diverso, segundo Sousa Santos e Meneses. Para os autores, essa diversidade, 
[...] longe de ser algo negativo, representa um enorme enriquecimento das capacidades humanas para conferir inteligibilidade e intencionalidade às experiências sociais. A pluralidade epistemológica do mundo e, com ela, o reconhecimento de conhecimentos rivais dotados de critérios diferentes de validade tornam visíveis e credíveis espectros muito mais amplos de acções e de agentes sociais. (SOUSA SANTOS; MENESES, 2009, p. 12).

Para que possamos contemplar essa diversidade, subjacente à noção de uma ecologia de saberes, considero que seja crucial, portanto, que pesquisas em contextos de ensino e aprendizagem se pautem por critérios dos quais não podem mais se esquivar: a) situcionalidade e historicidade, posto que a investigação não ocorre em um vácuo sociocultural. É preciso situá-la e discuti-la à luz de um contexto social, cultural e histórico; b) criticidade, visto que toda pesquisa suscita do pesquisador uma perspectiva crítica, não apenas sobre os discursos dos quais faz uso em sua investigação (como são dirigidos? para quem?), mas também sobre os (possíveis) sujeitos envolvidos (sobre o que estes pensam, sentem, desejam etc.) e suas práticas, em que perpassam sempre relações de poder. Nessa perspectiva, a pesquisa não pode se mais vista como um espaço de conhecimento monolítico, mas, ao contrário, como uma episteme, que, como propõe Foucault,

\begin{abstract}
[...] abre um campo inesgotável e não pode nunca ser fechada; não tem por finalidade reconstituir o sistema de postulados a que obedecem todos os conhecimentos de uma época, mas sim percorrer um campo indefinido de relações. Além disso, a episteme não é uma figura imóvel que, surgida um dia, seria convocada a apagar-se bruscamente: é um conjunto indefinidamente móvel de escansões, defasagens, coincidências, que se estabelecem e se desfazem. A episteme, ainda, como conjunto de relações entre ciências, figuras epistemológicas, positividades e práticas discursivas, permite compreender o jogo das coações e das limitações que, em um momento determinado, se impõem ao discurso; mas essa limitação não é aquela que, negativa, opõe ao conhecimento a ignorância, ao raciocínio a imaginação, à experiência já acumulada a fidelidade, às aparências, e às inferências e às deduções o devaneio; a episteme não é o que se pode saber em uma época, tendo em conta insuficiências técnicas, hábitos mentais, ou limites colocados pela tradição; é aquilo que, na positividade das práticas discursivas, torna possivel a existência das figuras epistemológicas e das ciências. (FOUCAULT, 2008 [1966], p. 214-215).
\end{abstract}

\title{
Considerações finais
}

Tomando como base uma noção plural de epistemologia, que explora e lida com a noção foucaultiana de savoir, amparada pelo conceito de letramento crítico, procurei realizar neste artigo uma metadiscussão epistemológica, ao discorrer sobre o processo de construção de conhecimentos no próprio ato de fazer pesquisa em contextos de ensino e aprendizagem, a partir da perspectiva de uma ecologia de saberes. Com isso, busco repensar a pesquisa sob dois pontos que considero fundantes: o primeiro é o seu caráter qualitativo. Nesse sentido, os critérios acima propostos (situcionalidade, historicidade e criticidade) só poderiam ser contemplados por meio de pesquisas qualitativas, em que se busca descrever e compreender o mundo das práticas dos participantes envolvidos na investigação, considerando, sobretudo, 
as vozes e as perspectivas dos sujeitos, mas não apenas, para registro e posterior interpretação do pesquisador: as vozes e os valores dos sujeitos envolvidos fazem parte da tessitura da própria metodologia da investigação. Assim, diferentemente de pesquisas quantitativas relacionadas à linguagem e educação, que lidam com dados coletados em escolas do ponto de vista estatístico, a pesquisa de caráter qualitativo procuraria trazer à tona os contextos específicos de atuação dos participantes e suas identidades, em que afloram seus valores, expectativas, anseios, dúvidas e dificuldades.

Um olhar qualitativo para a pesquisa, do mesmo modo, não nos faz olvidar que as relações entre teoria e prática não são elementos estanques; são partes constitutivas de um processo de investigação complexo que, mais do que promover um novo olhar sobre um determinado objeto de pesquisa, possibilita construir um novo objeto de pesquisa, uma vez que o percurso de investigação, no embate contínuo entre teoria e prática, nos leva rever e até inovar no processo de produção de pesquisa.

0 segundo ponto fundante, decorrente do primeiro, porém não redutivel a ele, é o seu caráter socioeducacional e sociopolitico. Isso porque a realização de pesquisas empíricas em contextos de ensino e aprendizagem por meio do uso de TDIC pode contribuir para o desenvolvimento da educação como um todo, tanto a básica, pois estaria disposta a buscar entender e atuar em diversas situações e práticas de letramentos, quanto a superior, porquanto possibilita, de fato, aliar e trabalhar juntos os três pilares que constituem a universidade pública brasileira: ensino, pesquisa e extensão.

Essa tentativa de estabelecer uma relação simbiótica entre os três pilares talvez seja a resposta para a pergunta que levantei no começo deste artigo: dos trabalhos produzidos na academia (artigos, monografias, dissertações e teses), quantos são, de fato, compartilhados com os sujeitos participantes das pesquisas que os geraram, não se limitando a serem usados para engordar o Currículo Lattes em apresentações de congressos e em publicações de revistas acadêmicas nacionais e internacionais?

A pergunta levantada não é apenas uma crítica à academia ou aos seus pesquisadores (entre os quais me incluo), pois cada um de nós pesquisadores sabe o quanto também somos cobrados por órgãos de fomento, cuja lógica quantitativa-produtivista nos impele cada vez mais a produzir, produzir e produzir, sem que a qualidade e muito menos o retorno aos maiores interessados daquilo que se produz sejam necessariamente a principal motivação.

Penso que a saída sociopolítica possa ser a de começarmos a ousar e pensar o próprio processo de produção acadêmica dentro de outra lógica - a la Slow Science? ${ }^{6}$ No entanto, essa lógica não estaria restrita apenas à ideia de produzir mais lentamente ou em menor quantidade, mas a todo um modus operandi que envolve a perspectiva aqui discutida de uma ecologia de saberes, isto é, não apenas na perspectiva de produção de connaissance, mas de uma verdadeira utopia de interconhecimento, que reconheça e lide com a diversidade de saberes (epistemologias, no plural), mas que seja, ao mesmo tempo, menos produtivista (e, com isso, mais produtiva), mais humana e, consequentemente, mais ética.

6- 0 movimento Slow Science, iniciado por cientistas na Alemanha em 2010, e já com milhares de signatários em todo o mundo, constitui-se em torno da ideia de que a "ciência precisa de tempo para pensar. A ciência precisa de tempo para ler e tempo para falhar". A esse respeito, ver http://slow-science.org/ 


\section{Referências}

CERVETTI, Gina, PARDALES, Michael J.; DAMICO, James S. A tale of differences: comparing the traditions, perspectives and educational goals of critical reading and critical literacy. Reading Online, v. 4, n. 9, Apr. 2001. Disponível em: <http://www.readingonline.org/articles/art_index.asp?HREF=articles/cervetti/ index. html>. Acesso em: 20 jun. 2011.

FOUCAULT, Michel. A arqueologia do saber. Tradução de Luiz Felipe Baeta Neves. Rio de Janeiro: Forense Universitária, 2008 [1966].

FOUCAULT, Michel; DELEUZE, Gilles. Os intelectuais e o poder: conversa entre Michel Foucault e Gilles Deleuze. In: FOUCAULT, Michel (Org.). Microfísica do poder. Tradução de Roberto Machado. 9. ed. Rio de Janeiro: Graal, 1982. p. 69-78.

FREIRE, Paulo. Education as the practice of freedom. Tradução de M. B. Ramos. In: Education for critical consciousness. New York: The Continuum Publishing, 1982. p. 1-84.

GEE, James Paul. Social linguistics and literacies: ideology in discourses. 2. ed. London: Taylor \& Francis, 1996.

LUKE, Allan. Foreword [Prefácio]. In: McLAUGHLIN, Maureen; DEVO0GD, Glenn. Critical literacy: enhancing students' comprehension of text. New York: Scholastic, 2004. 1 p.

O'REILLY, Tim. What is Web 2.0?: Design patterns and business models for the next generation of software. 2005. Disponível em: <www.oreillynet.com/pub/a/oreilly/tim/news/2005/09/30/what-is-web-20.html>. Acesso em: 4 abr. 2008.

PINHEIRO, Petrilson Alan. Construção multimodal de sentidos em um vídeo institucional: (novos) multiletramentos para a escola. Veredas, Juiz de Fora, v. 19, n. 2, p. 209-224, 2015. Disponível em: <http://www.ufjf.br/revistaveredas/files/2015/04/12-PINHEIRO.pdf>. Acesso em: 20 fev. 2016.

PINHEIRO, Petrilson Alan. Práticas colaborativas de escrita via internet: repensando a produção textual na escola. Londrina: Eduel, 2013.

PINHEIRO, Petrilson Alan; FELÍCIO. Rosane de Paiva. Copiar-colar e remix: o que a escola tem a ver com isso? Calidoscópio, São Leopoldo, v. 14, n. 1, p. 59-69, 2016. Disponível em: <http://revistas.unisinos.br/ index.php/calidoscopio/article/view/cld.2016.141.05/5198 >. Acesso em: 29 dez. 2016.

PINHEIRO, Petrilson Alan; GOMES, Cláudia. Multi/novos letramentos em ambiente digital: uma análise do Google Search Education. Revista do GEL, São Paulo, v. 12, n. 1, p. 109-138, 2015. Disponível em: <http:// revistadogel.gel.org.br/rg/article/view/406/422>. Acesso em 12 set 2016.

PINHEIRO, Petrilson Alan; RICARTE, Lidiany Teotonio. 0 uso do software Scratch na escola pública: discussão da noção de autoria e remixagem na contemporaneidade. In: SIMPÓSIO INTERNACIONAL DE ENSINO DE LÍNGUA PORTUGUESA (SIELP), 2014, Uberlândia. Anais do SIELP. Uberlândia: Edufu, 2014. p. 1-10. Disponível em: <http://www.ileel2.ufu.br/anaisdosielp/wp-content/uploads/2014/11/307.pdf>. Acesso em: 09 set. 2016. 
PRENSKY, Marc. Digital Natives, Digital Immigrants. On the Horizon, MCB University Press, v. 9, n. 5, p. 1-5, 2001.

SIGNORINI, Inês. Epistemologias da pesquisa no campo aplicado dos estudos da língua(gem). Apresentação. Revista Delta, São Paulo, v. 31, n. esp. p. iii-vi, 2015. Disponível em: <http://revistas.pucsp.br/index.php/ delta/issue/current>. Acesso em: 20 ago. 2015.

SILVA, Kleber Aparecido; SANTOS, Leandra Ines Seganfredo; JUSTINA, Olandina Della. Entrevista com Kanavillil Rajagopalan: ponderações sobre linguística aplicada, política linguística e ensino-aprendizagem. Revista de Letras Norte@mentos - Revista de Estudos Linguísticos e Literários. Edição 08 - Estudos Linguísticos, Sinop, 2011. Disponível em: <http://projetos.unemat-net.br/revistas_eletronicas/index.php/ norteamentos>. Acesso em: 20 ago. 2015.

SOUSA SANTOS, Boaventura de. A gramática do tempo. Porto: Afrontamento, 2006.

SOUSA SANTOS, Boaventura de; MENESES, Maria Paula (Org.). Epistemologias do Sul. Coimbra: Almedina, 2009.

SØBY, Morten. Digital competence - from education policy to pedagogy: the Norwegian context. In: LANKSHEAR, Colin; KNOBEL, Michele. Digital literacies. New York: Peter Lank, 2008. p. 119-150.

STREET, Brian V. Abordagens alternativas ao letramento e desenvolvimento. Teleconferência Brasil sobre 0 letramento, outubro de 2003.

STREET, Brian V. Literacy in theory and practice. Cambridge: CUP, 1984.

Recebido em: 30.05.2017

Revisões em: 29.11.2017

Aprovado em: 06.02.2018

Petrilson A. Pinheiro é professor doutor do Instituto de Estudos da Linguagem da Universidade Estadual de Campinas (Unicamp), São Paulo, Brasil, e coordenador do Grupo de Pesquisa do CNPQ Multiletramentos na escola por meio da hipermídia. 